\section{Relações entre duas dimensões fundamentais da vida: saúde mental e religião}

\author{
Relationships between \\ two fundamental \\ dimensions of life: \\ mental health \\ and religion
}

Embora já tenhamos no Brasil grupos de pesquisa autônomos e produtivos, a colaboração entre pesquisadores brasileiros entusiasmados e inteligentes e pesquisadores norte-americanos e europeus com uma considerável bagagem em pesquisas empíricas é, possivelmente, um dos caminhos mais seguros para o crescimento e aperfeiçoamento da pesquisa em psiquiatria e saúde mental no País, principalmente para novas áreas de investigação.

No presente número da Revista Brasileira de Psiquiatria, temse uma boa amostra desse tipo de colaboração fértil. Trata-se de revisão ampla, cuidadosa e crítica sobre as relações entre religião, saúde mental, bem estar psicológico e transtornos mentais. A presente revisão, por sua vez, é baseada num trabalho prévio, exaustivo e aprofundado, realizado pelos principais pesquisadores norte-americanos da área; Koenig, McCullough e Larson. ${ }^{1}$ Eles sintetizaram em seu livro o resultado de 850 artigos publicados ao longo do século XX. Além disso, esta revisão atualizada acrescenta novos trabalhos internacionais, publicados já no presente século e também alguns estudos brasileiros.

Nesta revisão de Moreira-Almeida, Lotufo Neto e Koenig, são demonstrados os efeitos positivos de um maior envolvimento religioso sobre a saúde mental. Tanto os numerosos estudos transversais como alguns estudos de seguimento bem conduzidos evidenciam que, de modo geral, sujeitos que se envolvem com a vida e atividades religiosas, como freqüência a cultos, orações e leitura de textos religiosos, e se consideram "pessoas mais religiosas" apresentam maior bem estar psicológico e menores prevalências de depressão, uso, abuso ou dependência de substâncias, ideação e comportamentos suicidas.

Vários mecanismos têm sido propostos e investigados em relação a como a religiosidade agiria positivamente sobre a saúde mental. É possível que um conjunto de fenômenos distintos aja em sinergismo: o apoio social dos grupos religiosos, a disponibilidade de um sistema de crenças que propicia sentido à vida e ao sofrimento, o incentivo a comportamentos saudáveis e regras referentes a estilos de vida propiciadores da saúde (relacionados à alimentação, ao uso de substâncias, ao comportamento sexual, à criação dos filhos, etc.).

Uma das limitações desta linha de pesquisa, entretanto, é o fato de grande parte das pesquisas que demonstram essa ação positiva da religião ter sido realizada, quase que exclusivamente, no contexto cultural anglo-saxão (principalmente nos EUA, Canadá e Europa ocidental). Além disso, a maior parte das pesquisas realizadas nesses contextos, com métodos epidemiológicos e psicométricos, não realiza, concomitantemente ao teste da relação entre variáveis "congeladas" de religião e saúde mental, um estudo cuidadoso do contexto sociocultural e simbólico da experiência religiosa para as pessoas envolvidas. Não obstante, há uma tendência de muitos autores dessa linha de pesquisa a generalizar amplamente seus achados; não é a religiosidade específica de determinados grupos cristãos norte-americanos, num momento histórico e contexto social que se associa à meIhor saúde mental, é a religião, categoria universal e homogênea, que teria tal implicação.

Toda e qualquer religiosidade surge em contextos históricos, socioeconômicos, políticos e culturais determinados e tem, portanto, sentidos específicos para cada um desses contextos. Ela 
é, desta forma, intrinsecamente uma dimensão social e cultural da experiência humana. ${ }^{2}$ Além disso, a vida religiosa é constituída por símbolos arbitrários, não-naturais, que são formulados por grupos sociais específicos, grupos esses que lidam e são "conduzidos" por tais símbolos, também de forma específica. ${ }^{3}$ Assim, é de se esperar que diferentes formas de religiosidade, em distintos contextos sociais e culturais, tenham significações e implicações diferenciadas para a vida das pessoas, sua subjetividade e saúde mental.

De modo geral, a pesquisa sobre religiosidade e saúde mental realizada na América do Norte, onde prepondera uma perspectiva marcadamente individualista da vida social e religiosa, ${ }^{4}$ tende também a tratar a religião e a religiosidade como uma dimensão individual e estritamente psicológica e, quase sempre, descontextualizada de suas origens socioculturais e de sua historicidade. Abordar a religiosidade como algo homogêneo e universal, torná-la quase um "fenômeno natural", diretamente analisável e generalizável por procedimentos epidemiológicos e psicométricos, implica no risco de se perder o que há de mais original e próprio dessa dimensão da experiência humana: o seu caráter social, histórico, essencialmente simbólico.

Quando se fala em religiosidade e quando se articula tal objeto com o bem estar psicológico e com a ocorrência de transtornos mentais é possível que isto tenha implicações diferentes para cristãos protestantes ou católicos dos países ocidentais, para budistas, para membros de religiões animistas da África ou para membros de outros grupos étnicos, assim como para membros de pequenas seitas e subgrupos ocidentais. Da mesma forma, nos países ocidentais, a religiosidade parece ter significados, contornos e implicações diferenciadas para pessoas de diferentes grupos sociais, interagindo com dimensões como classe social, modernização individual, gênero, grupo étnico, status de grupo majoritário ou de minoria excluída. Por exemplo, uma minoria como a dos homossexuais do gênero masculino em determinados contextos têm um interesse considerável pelo envolvimento com a religiosidade, ${ }^{5}$ mas são quase sempre intensamente discriminados pelas principais religiões ocidentais. Isto produz um impacto contraditório e, eventualmente, gerador de conflito e sofrimento.

A revisão apresentada neste número trata, na medida que o espaço de um artigo permite, de algumas das dificuldades e complexidades que o tema implica. Seu principal valor é demonstrar o quão marcada e profundamente a vida religiosa se relaciona com a saúde e os transtornos mentais. Oxalá pesquisadores e clínicos brasileiros, após lerem esta competente revisão, tornem-se mais atentos a dimensões culturais fundamentais da vida de seus sujeitos de pesquisa e pacientes, para além dos diagnósticos, e passem a incluir a avaliação dessa dimensão em seus estudos epidemiológicos e na prática clínica.

Paulo Dalgalarrondo Departamento de Psicologia Médica e Psiquiatria, Faculdade de Ciências Médicas, Universidade Estadual de Campinas (UNICAMP), Campinas (SP), Brasil

\section{Referências}

1. Koenig HG, McCulloug ME, Larson DB. Handbook of religion and health: a century of research reviewed. New York: Oxford University Press; 2001.

2. Byrne P. Religion: definition and explanation. In: Smelser NJ, Baltes PB, eds. International Encyclopedia of the Social and Behavioral Sciences. Amsterdam: Elsevier; 2001.

3. Geertz C. A religião como sistema cultural. In: Geertz C. A interpretação das culturas. Rio de Janeiro: Zahar Editores; 1978.

4. Deconchy JP. Théories et allegories en psychologie de la religion. Archives de Sciences Sociales des Religions. 1987;64(2):179-93.

5. Sherkat ED. Sexuality and religious commitment in the United States: an empirical examination. J Sci Study Religion. 2002;41(2):313-24. 